\title{
Effects of Prenatal Methamphetamine Exposure on Birth Outcomes, Brain Structure, and Neurodevelopmental Outcomes
}

\author{
Youyou Zhang a, b Fuhua Gong ${ }^{\mathrm{a}}$ Pan Liu $^{\mathrm{a}} \mathrm{Ya} \mathrm{He}^{\mathrm{a}}$ Hui Wang ${ }^{\mathrm{a}}$ \\ aDepartment of Geriatrics Neurology, The Second Affiliated Hospital, School of Medicine, Xi'an Jiaotong University, \\ Xi'an, China; ${ }^{b} \mathrm{NHC}$ Key Laboratory of Forensic Science, Xi'an Jiaotong University, Xi'an, China
}

\section{Keywords}

Prenatal exposure · Methamphetamine · Birth outcomes ·

Brain network · Neurodevelopment

\begin{abstract}
This study reviews the findings from previous research on the effects of prenatal methamphetamine (MA) exposure on birth outcomes, brain structure, and neurodevelopmental outcomes of the offspring. These findings indicate that prenatal MA exposure may lead to shorter gestational age, lower birth weight, lower head circumference, and shorter body length of neonatal, structural brain changes, and impairment in cognitive development, motor development, inhibitory control, and attention of children from 1 to 15 years. Based on these findings of the previous cohort studies on the effect of prenatal MA exposure on the birth outcomes and childhood outcomes of the offspring, we conclude by discussing the shortcomings and inconsistencies of previous studies in each section. A multicenter, large-scale population-based prospective cohort study is needed to establish and seek the differences and similarities of the pathological changes in different systems among offspring prenatally exposed to MA in different periods. And the pathophysiology
\end{abstract} the method of omics technology in future. These efforts are of great significance to address the adverse health outcomes caused by prenatal MA exposure.

(c) 2021 S. Karger AG, Basel

\section{Introduction}

Methamphetamine (MA), a derivative of amphetamine, is a highly addictive psychostimulant and easily synthesized, which led to widespread abuse worldwide in recent decades. The world drug report 2017 indicate that the prevalence of MA abuse is second only to opioids and the harm of it is second only to cannabis [1]. The increasing use of MA represents a serious problem with physical, psychological, and societal damage [2,3]. Moreover, the MA use among pregnant women has increased consistent with the nationwide rise in use rates $[1,4-6]$. In the USA, statistics data show that only $17 \%$ of female drug abusers were primary MA users, but $38 \%$ had used MA during pregnancy because it decreases their appetite and helps them control their weight [7]. However, the MA use during pregnancy affects the embryo development because it

Correspondence to:

Youyou Zhang, tjf1289@126.com 
can easily cross the placental barrier [8]. And previous studies showed that prenatal MA exposure can also affect postnatal development of newborns [8-10]. The delayed development, structural brain changes, impaired neurodevelopment, and other defects were found both in clinical studies [8-12] and animal models [13, 14].

The purpose of this article is to describe the changes in the gestational age, birth weight, head circumference, and body length of neonates exposed prenatally to MA, the structural brain changes, and impairment in cognitive development, motor development, inhibitory control, and attention of children exposed prenatally to MA. And summarize the effects of prenatal MA exposure on birth outcomes, brain structure changes, and neurodevelopmental outcomes then put forward the future research prospects.

\section{Birth Outcomes}

\section{Gestational Age}

Gestational age at birth, specifically the gestational age in and of itself is independent of substance exposure, is an important factor in anticipating infant's medical risks and nursing care needs [15]. And the association between gestational age and cognitive impairment was observed in previous population analysis $[16,17]$. In previous studies, the gestational age at birth was shorter among the MAexposed infants compared to nonexposed infants in general. Statistically significant difference was found in the most previous studies [18-24], while the data reported by some studies $[25,26]$ revealed a nonstatistically significant difference in gestational age at birth among the MAexposed group compared to the controls. What is more, preterm birth (gestational age $<37$ weeks) is a major cause of neonatal morbidity and mortality [27] and has been associated with the risk of disease in adulthood life [28]. The meta-analysis conducted by Ladhani [9] indicate that prenatal MA exposure can increase the risk of preterm birth. To sum up, the effect of prenatal MA exposure on normal gestational age and preterm birth can increase the health risk of the offspring and the use of MA during pregnancy results in a deterioration of neonatal birth weight, head circumference, body length.

\section{Birth Weight}

Low birth weight, an important indicator of prenatal environment, has been associated with differential risk for neonatal mortality $[29,30]$, neurodevelopment and behavioral problems [31, 32], and other diseases [33, 34].
Infants born from MA-abusing mothers were found to have lower birth weight in previous studies. Statistically significant difference was found in the data reported by Wouldes et al. [25] and meta-analyses of 4 studies [22, 35-37] that revealed prenatal MA exposure can decrease the infant birth weight. These results suggest that the lower birth weight caused by prenatal MA exposure maybe a risk factor of neonatal mortality and childhood and adult diseases.

\section{Head Circumference}

The head circumference is an important factor for evaluating intrauterine brain development and is related to the delayed cognitive and motor development of neonatal [38-40]. Infants prenatally exposed to MA have tended to show a significant decrease in head circumference $[26,35,41-43]$. Above results indicated that the findings of reduced head circumference following MA exposure suggest an increased risk of intrauterine brain growth restriction.

\section{Birth Length}

The U-shaped relationship between the birth length and risk of hospitalization early in life due to all causes was found among Japanese children [44]. And the relationship between a lower birth length and risk of overweight and obesity in boys was found in the study which involved 747 children in southeastern Poland [45]. Prenatal MA exposure affecting the birth length of infants was found by Abar et al. [18], Eze et al. [24], Lagasse et al. [41], Diaz et al. [21], Shah et al. [26], and the data in some studies also show a decreasing tendency but there was no statistical difference $[19,22,25]$.

\section{Infant Medical Outcomes}

The infant medical outcomes were influenced by MA exposure during pregnancy. The Apgar score was firstly reported by Dr Apgar [46] and the scoring system comprises 5 components including color, heart rate, reflexes, muscle tone and respiration, which provides a standardized assessment for newborn infant immediately after delivery [47]. Compared to unexposed infants, lower Apgar score and higher neonatal mortality were found in MAexposed infants, which was reported by a single-site chart review from 2000 to 2006 conducted in a tertiary care, urban, academic medical center [48]. The systematic review on effect of MA on pregnancy outcome conducted by Kalaitzopoulos et al. [49] show that neonatal prenatally exposed to MA having a lower Apgar score. Billing et al. [50] found that prenatal MA exposure can cause 
temporary drowsiness in the infants during the first month after birth, and an increased rate of medical care mainly because of infections within the 12 months. Poor suck, NICU admission, and child protective services involvement were the main characteristics reported by Shah et al. [26], and the infant medical complications and conditions in the MA-exposed group were less likely to be breastfed and more likely to have a central nervous system diagnosis, autonomic stress, and central nervous system hypertonia at discharge. To better understand the integrity of the central nervous system and maturity of the infant, the NICU Neurobehavioral Scale (NNNS) examination, an assessment of neurologic, behavior, and stress/abstinence neurobehavioral function, was administered within 5 days of life in exposed infants in the prospective, controlled longitudinal Infant Development, Environment, and Lifestyle (IDEAL) study [41]. And the data show that prenatal MA exposure was associated with increased physiological stress, especially in the heavy MA use group [51]. What is important, the association between the NNNS scores and MA use during each trimester was different, greater total stress/abstinence and physiological stress were found in the first trimester MA use group, and increased lethargy and hypotonicity were found in the third trimester MA use group among the infants in the USA and New Zealand [41, 51]. Beside the central nervous system disease, the defects of the musculoskeletal, abdominal wall, and cardiac were also observed in the IDEAL study [26]. However, the infant medical outcomes of prenatal MA exposure are controversial. Oei et al. [52] found that the incidence of neonatal complications did not differ significantly between MA-exposed and unexposed infants in the state of New South Wales and the Australian Capital Territory. And the frequency of congenital anomalies was not significantly increased in infants prenatally exposed to MA was found by Little et al. [35]. These results indicate that the factors including race/ethnicity, severity of MA exposure, socioeconomic factors and so on, which may be associated with infant medical outcomes need to be further studied.

In this section, we conclude that MA exposure during pregnancy has different degrees of impact on gestational age, physiological conditions after birth and adverse birth outcomes (Table 1). Although other exposure factors such as smoking, drinking, and other substances were included as control or correction factors in some studies, whether prenatal MA exposure as a risk factor in the adverse birth outcomes of infant is still inconsistent. Even more, whether the degree/dosage of MA exposure and the timing of MA exposure during pregnancy affect the ges-

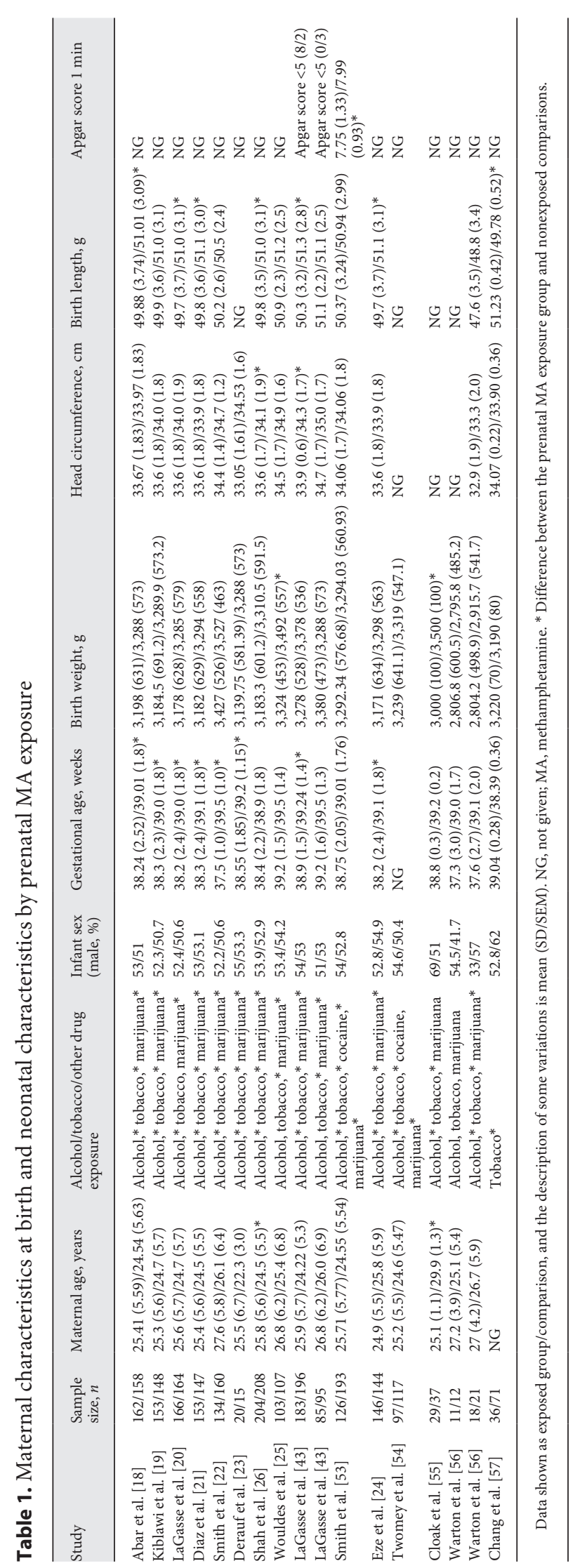


tational age, birth weight and length, and the head circumference of the offspring is unknown. At the same time, the sample size is small and the lack of multicenter cooperation is also the shortage in previous studies. In view of the previous findings and shortcomings, based on the growing concerned public health problem of MA exposure during pregnancy, the international multicenter cooperation is called for in-depth research to clarify the differences of effects of prenatal MA exposure on the birth outcomes of infants and children in different ethnic/regions, so as to provide reference for the health education among women of gestational age and intervening measures for the health of the offspring.

\section{Structural Brain Changes}

\section{Subcortical and Cortical Brain Volumes and \\ Thickness}

Prenatal exposure to MA affects the brain development of neonate and children. Previous neuroimaging studies [55, 56, 58-66] have identified the changes of subcortical and cortical brain volumes and thickness which were determined and calculated automatically by using magnetic resonance imaging. For this preliminary study, we global intracerebral brain volumes, subcortical brain structure, and cerebellum. For example, the findings in children with prenatal MA exposure are as follows: volume reductions in the caudate nucleus, globus pallidus, putamen, hippocampal, striatum, thalamus, parieto-occipital, and anterior prefrontal cortices; volume increases in the anterior and posterior cingulate, ventral and medial temporal, and perisylvian cortices; cortical thickness increases in perisylvian, orbital frontal cortices, and superior parietal, while reduced cortical thickness was found in caudal, middle frontal, and rostral anterior cingulate [59]. Interestingly, Roos et al. [60] found that the changes in the areas of striatal, frontal, and parietal are in part gender dependent. We found that the studies examined the effects of prenatal MA exposure on brain structural changes were mainly focused on older children. However, the rapid development and growth of the brain that occurs during the organizational phase after birth. So that it is important to explore whether these changes can be detected in the newborn, the cohort involved 39 infants (18 MA exposed and 21 controls) in South Africa conducted by Warton et al. [56] and the data demonstrate that reduced caudate and thalamus volumes in neonates are consistent with previous findings in children.

\section{Brain Network Connectivity}

White matter microstructure plays an important role in the connections among pairs of target regions such as striatal-amygdala regions and frontal-amygdala regions. What is more, white matter bundles associated with the fiber networks including commissural fibers, left and right projection fibers, and left and right association fibers. In previous studies, white matter microstructural integrity in MA-exposed children was mostly evaluated by using diffusion tensor imaging and analyzed by using apparent diffusion coefficient, fractional anisotropy (FA), mean diffusivity, radial diffusivity, and axial diffusivity. Cloak et al. [55] found that lower diffusion in white matter which may reflect more compact axons or greater dendritic or spine density of children prenatally exposed to MA. The changes of white matter microstructure and structural connectivity between MA-exposed and unexposed children aged 6 to 8 years were identified by Roos et al. [61, 62], they found that prenatal MA exposure disrupted integrity of tracts traversing frontal, striatal and limbic regions [61] and decreased connectivity in frontal and limbic hubs, increased connectivity in the superior parietal cortex and striatum [62]. Importantly, Warton et al. $[63,64]$ found that prenatal MA exposure leads to changes of corticostriatal white matter and fiber networks in neonates. Roussotte et al. [65] found that both caudate seeds showed reduced positive connectivity with frontal regions while the left putamen seed showed increased connectivity with prefrontal regions in children prenatally exposed to MA. Chang et al. [57, 67] found that lower FA in anterior corona radiata which is consistent with the findings by Roos et al. [61] and Warton et al. [56], but the findings by Colby et al. [68] and Cloak et al. [55]. The difference may be due to changes in brain development over time, age range, regional inconsistencies, diffusion tensor imaging parameters and so on. However, these results suggest that prenatal MA exposure affects the brain network connectivity in neonates and children, and future longitudinal studies need to be conducted to clarify whether prenatal MA exposure leads to lower or higher FA at different stages of brain maturation in different regions.

In this section, we obtained the results of previous studies on the changes of brain structure and brain network connectivity in children prenatally exposed to MA (Table 2). Most of the studies focused on older children while only a few studies evaluated the brain structure of newborn infants. As we know, the development and differentiation of fetal brain are a complex and delicate process, and the second and the third trimester of pregnancy 
Table 2. Effects of prenatal MA exposure on brain structure

\begin{tabular}{|c|c|c|c|c|c|}
\hline Study & $\begin{array}{l}\text { Sample } \\
\text { size, } n\end{array}$ & Age, years & \multicolumn{3}{|l|}{ Structural brain changes } \\
\hline Warton et al. [56] & $18 / 21$ & $\begin{array}{l}1 \text { month/ } \\
1 \text { month }\end{array}$ & $\begin{array}{l}\mathrm{L} \text { and } \mathrm{R} \text { caudate } \\
\mathrm{L} \text { and } \mathrm{R} \text { thalamus }\end{array}$ & NG & NG \\
\hline Sowell et al. [59] & $21 / 27$ & $\begin{array}{l}9.66(1.85) / \\
10.15(2.90)\end{array}$ & $\begin{array}{l}\mathrm{L} \text { and R striatal }{ }^{\# \#} \\
\mathrm{~L} \text { occipital brain regions } \text { s\# }^{\#} \\
\mathrm{R} \text { occipital fusiform cortex } \\
\mathrm{L} \text { and R dorsal parietal cortex } \\
\mathrm{L} \text { and R cingulate cortices } \\
\mathrm{L} \text { and R perisylvian cortices** }\end{array}$ & NG & NG \\
\hline Roos et al. [60] & $18 / 18$ & $6 / 6$ & L putamen** & $\begin{array}{l}\text { L inferior parietal, pars } \\
\text { opercularis, and precuneus }{ }^{\# \#}\end{array}$ & NG \\
\hline Roos et al. [62] & $17 / 16$ & $\begin{array}{l}6-8.8 / \\
6-8.8\end{array}$ & $\begin{array}{l}\text { R putamen** } \\
\mathrm{L} \text { amygdala }{ }^{\# \#}\end{array}$ & $\begin{array}{l}\text { L superior parietal }{ }^{* *} \\
\text { L precentral } \\
\text { R caudal middle frontal }^{\# \#} \\
\mathrm{R} \text { rostral anterior cingulate }\end{array}$ & $\begin{array}{l}\text { Decreased connectivity in frontal and limbic } \\
\text { hubs } \\
\text { Increased connectivity in the superior parietal } \\
\text { cortex and striatum } \\
\text { Less change in segregation of structural } \\
\text { networks }\end{array}$ \\
\hline Warton et al. [63] & $11 / 12$ & $\begin{array}{l}1 \text { month/ } \\
1 \text { month }\end{array}$ & NG & NG & $\begin{array}{l}\text { Lower FA in several connections between the } \\
\text { striatum and midbrain, orbital frontal cortex, } \\
\text { and associated limbic structures }\end{array}$ \\
\hline Cloak et al. [55] & $29 / 37$ & $\begin{array}{l}3-4 / \\
3-4\end{array}$ & NG & NG & $\begin{array}{l}\text { Higher FA in } \mathrm{L} \text { frontal white matter } \\
\text { Lower ADC in R frontal white matter } \\
\text { Lower ADC in L and R parietal white matter }\end{array}$ \\
\hline Roussotte et al. [65] & $19 / 18$ & $\begin{array}{l}7-13 / \\
7-15\end{array}$ & NG & NG & $\begin{array}{l}\text { Putamen seeds showed increased connectivity } \\
\text { with the frontal brain } \\
\text { Caudate seeds showed decreased connectivity } \\
\text { with some regions }\end{array}$ \\
\hline
\end{tabular}

L, left; R, right; OFC, orbital frontal cortex; ADC, apparent diffusion coefficient; FA, fractional anisotropy; MD, mean diffusivity; RD, radial diffusivity;

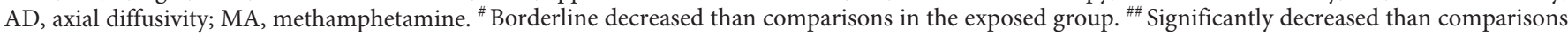
in the exposed group. ${ }^{*}$ Borderline increased than comparisons in the exposed group. ${ }^{* *}$ Significantly increased than comparisons in the exposed group.

are the key stages of fetal brain development. Combined with findings of the correlation between prenatally MA exposure and adverse birth outcomes in the first section, it is speculated that any developmental abnormality dur- ing pregnancy may lead to long-term mental retardation and even affect the quality of life in perinatal and late childhood. However, there is no research on the structure and network connectivity of fetal brain during pregnan- 
cy. Based on the development of high resolution, nonradiation and noninvasive brain function detection technology, we hope that the map of fetal brain volume, structural connectivity and functional connectivity, as well as the temporal dynamic changes of brain network connectivity development during pregnancy in the prenatal MA exposure group was established in the future study. So as to provide scientific basis for determining whether MA exposure during pregnancy is the cause of fetal brain abnormalities.

\section{Neurodevelopmental Outcomes}

The Swedish cohort was the first follow-up study on the effects of prenatal MA exposure on affective, behavioral, and cognitive outcomes and the researchers assessed children longitudinally from birth to 14 years of age. The data from 65 children with continuous MA exposure throughout gestation in that cohort show that emotional disturbance was found at age 1 [50], child's adjustment was disrupted at age 4 [68], increased incidences of aggressive behavior and peer-related problems were found at age 8 [69], the intellectual capacity of $12 \%$ children below what was normal for their biological age at 10 years old [70], mean points in mathematics, Swedish language and sports were statistically below normal at the age of 14 years [71]. These data suggest that prenatal MA exposure will influence children at least up to the age of 14-15 years.

The IDEAL study designed to determine maternal outcome and child growth and developmental findings following prenatal MA exposure from birth up to age 7.5 years. Lower grasping scores in the MA exposure group was found from age 1 to age 3 [72]. LaGasse et al. [20] found that increased emotional reactivity and anxiety/depression at age 3 and 5, and increased externalizing behavior $[20,54]$ and the risk of attention-deficit hyperactivity disorder at age 5 in children prenatally exposed to MA. Heavy prenatal MA exposure is related to subtle deficits in inhibitory control among 66-month-old children [23]. The effects of prenatal MA exposure on the incidence of inattention and impulsivity at 5.5 years of age in children were identified as these children exhibit indicators of risk for attention-deficit hyperactivity disorder and warrant monitoring [19]. The relationship between prenatal MA exposure and behavior problems at age 7.5 years in 290 children with complete child behavior checklist data analyzed by Eze et al. [24] was that 146 children prenatally exposed to MA with increased externalizing, rule-breaking behavior, and aggressive behavior. Children prenatally exposed to MA were 2.8 times more like- ly to have cognitive problems than unexposed which suggest that prenatal MA exposure may affect academic achievement of the offspring and lead to increased negative behavioral outcomes [21].

The Griffiths Mental Developmental Scales (GMDSs) examination provides an overall developmental assessment of the child's functioning including locomotor, personal-social, hearing and language, eye-hand coordination and performance [73]. The general quotients of GMDS were lower both in the cohort of prenatally MAexpose infants in Western Australian and the pilot cohort of 15 children aged 2-4 years in South African. The neurodevelopmental outcomes among the cohort of Western Australian infants were that $38.7 \%$ of the infant as having a developmental delay at age 1 . The weakest functioning of GMDS was in the language subscale, and the functioning of GMDS in 56.2\% MA-exposed children were below the mean in at least one subscale [74]. The results of functioning of GMDS in South African indicate that children prenatally exposed to MA having poorer performance on the subscale of personal-social and eye-hand coordination [75]. However, the findings in the 2 cohorts' contrast those reported by Smith et al. [72] that only certain fine motor deficits in MA-exposed children at 1 year of age were found in the IDEAL study. These findings suggest that the study on effects of prenatal MA exposure on neurodevelopmental outcomes may warrant enhanced multicenter cooperation.

In this section, we concluded that prenatal MA exposure affect neuropsychiatric behaviors such as cognition, movement, emotion and so on in previous studies (Table 3). However, the longest follow-up time in the cohort study was $14-15$ years, and there is a lack of longer followup results to further clarify whether MA exposure during pregnancy affect neurocognitive and motor functions in adulthood and old age. Based on this research status, we hope to carry out more cohort studies on the effects of prenatal MA exposure on health and disease in youth, middle age and old age of the offspring. It is important to clarify the long-term outcomes of the offspring prenatally exposed to MA and to evaluate whether prenatal MA exposure is the risk factor of the fetal origins of adult disease.

\section{Outlook and Challenge}

Based on the findings of the previous cohort studies on the effect of prenatal MA exposure on the birth outcomes and childhood outcomes of the offspring, combined with the epidemiological data that the increasing illicit drugs abuse among women of childbearing age and the region- 
Table 3. Neurodevelopmental outcomes by prenatal MA exposure

\begin{tabular}{lll}
\hline Study/examination & Region & Neurodevelopmental outcomes \\
\hline Swedish cohort & Sweden & $\begin{array}{l}\text { Emotional disturbance at age 1; aggressive behavior (35\%) and poor adjustment (40\%) at age 4; aggressive } \\
\text { behavior (23\%), poor adjustment (40\%), and general assessment at age 8; one grade lower than indicated by } \\
\text { their biological age at age 10 (12\%) and age 14 (15\%); lower mean points in mathematics, Swedish language, and } \\
\text { sports at age 14 }\end{array}$ \\
\hline IDEAL study & USA and New & $\begin{array}{l}\text { Lower grasping scores at age 1; anxious/depressed problems, increased emotional reactivity, and attention } \\
\text { problems at age 3; anxious/depressed problems, increased emotional reactivity, externalizing and attention } \\
\text { deficit/hyperactivity disorder, and withdrawn behavior at age 5; inattention and impulsivity at 5.5 years; } \\
\text { increased externalizing, rule-breaking behavior, and aggressive behavior at age 7.5 }\end{array}$ \\
\hline $\begin{array}{l}\text { GMDS } \\
\text { examination }\end{array}$ & $\begin{array}{l}\text { Western Australia } \\
\text { and South Africa }\end{array}$ & $\begin{array}{l}\text { Developmental delay at 4 (33.7\%), 12 months (38.7\%), the weakest was the performance on language subscale, } \\
\text { and 56.2\% were below the mean in at least 1 subscale in Western Australian; poorer performance on the } \\
\text { personal-social subscale and eye-hand coordination, aggressive behavior, and attention-deficit/hyperactivity at } \\
\text { age 2-4 in South African }\end{array}$ \\
\hline
\end{tabular}

IDEAL, Infant Development, Environment, and Lifestyle; GMDSs, Griffiths Mental Developmental Scales; MA, methamphetamine.

al differences in the prevalence of MA and its derivatives abuse. It is necessary to perform a multicenter, large-scale population-based prospective cohort study, which will help to further analyze the risk factors of prenatal MA and its derivatives exposure, track the health information of the offspring prenatally exposed to MA and its derivatives in different periods, get the data of the offspring across geographic and ethnic regions to catalog the main differences and similarities among them. Although there will be a high lost visit rate, differences in medical standards, funding constraints and other difficulties, it is of great social significance to perform this work.

In addition to the basic information statistics of the population-based prospective cohort study, it is particularly important to study the pathological mechanism of adverse health outcomes of the offspring caused by MA exposure during pregnancy. To our best knowledge, yet little is known about the pathophysiology mechanism of prenatal MA exposure on adverse health outcomes. According to the latest research result of the IDEAL study, the epigenetic alterations in HSD11B2 were found as the first evidence that prenatal MA exposure acts as a stressor affects the long-term brain and behavioral development in children [76]. However, gene expression and regulation play an important role in the process of growth, development and pathological changes of human beings, which is regulated by methylation, transcription factors, miRNA and so on. With the development of biotechnology such as gene chips, genomics, and proteomics, it has been possible for a large-scale detection and analysis of the expression profiling and mapping biological molecules information of proteins and genes in recent years. Therefore, we hope that these techniques can be used to detect and screen the differentially expressed molecular markers of the offspring prenatally exposed to MA, and further analyze the possible regulatory mechanism of it.

Most importantly, the previous studies mainly focused on the effects of prenatal MA exposure on the nervous system of the offspring. However, there is a lack of relevant research reports on whether MA exposure during pregnancy affects the growth and development of the circulatory system, endocrine system, immune system, and other systems of the offspring. This work requires the participation of numerous departments, needs follow-up from specialist doctors, and more funding support. So that it is full of challenges to perform this important work.

In conclusion, some achievements have been made in previous studies on the effects of prenatal MA exposure on the birth outcome, brain structural network, and neurodevelopmental outcomes of the offspring, but the effects on other systems and the specific pathophysiological mechanism of these changes are not clear. A multicenter, large-scale population-based prospective cohort study needs to be performed in further research so as to evaluate the differences and similarities of the changes in different systems among offspring prenatally exposed to MA in different periods. And much more biomarkers and gene mutations should to be detected and analyzed by the method of omics technology. It is of great significance to establish the theoretical system of the effects of prenatal MA exposure on the health outcomes of the offspring. 


\section{Statement of Ethics}

This study is in accordance with international guidelines and was approved by the Xi'an Jiaotong University Ethics Committee.

\section{Conflict of Interest Statement}

The authors declare no conflicts of interest.

\section{Funding Sources}

This study was supported by NHC Key Laboratory of Forensic Science (Xi'an Jiaotong University) Open Projects Fund (Project no. 2020FYXH003).

\section{Author Contributions}

Youyou Zhang designed and coordinated the study, drafted the manuscript, and critically reviewed the manuscript; Fuhua Gong performed the literature search and data extraction; Pan Liu performed the literature search; Ya He reviewed the methodological quality and data extraction; and Hui Wang critically reviewed the manuscript.

\section{References}

1 United Nations Office on Drugs and Crime. World drug report 2017. United Nations publication; 2017. Sales No.: E.17.XI.6.

2 Richards JR, Laurin EG. Methamphetamine toxicity. In: StatPearls [Internet]. Treasure Island (FL): StatPearls Publishing; 2021.

3 Yasaei R, Saadabadi A. Methamphetamine. In: StatPearls [Internet]. Treasure Island (FL): StatPearls Publishing; 2021.

4 Arria AM, Derauf C, Lagasse LL, Grant P, Shah R, Smith L, et al. Methamphetamine and other substance use during pregnancy: preliminary estimates from the infant development, environment, and lifestyle (IDEAL) study. Matern Child Health J. 2006;10(3): 293-302.

5 Australian Institute of Health and Welfare. National drug strategy household survey 2016: detailed findings. Canberra: The Institute; 2017.

6 Smid MC, Metz TD, Gordon AJ. Stimulant use in pregnancy: an under-recognized epidemic among pregnant women. Clin Obstet Gynecol. 2019;62(1):168-84.

7 Marwick C. NIDA seeking data on effect of fetal exposure to methamphetamine. JAMA. 2000;283(17):2225-6.

8 Šlamberová R. Review of long-term consequences of maternal methamphetamine exposure. Physiol Res. 2019;68(Suppl 3):S21931

9 Ladhani NN, Shah PS, Murphy KE. Knowledge synthesis group on determinants of preterm/LBW births. Prenatal amphetamine exposure and birth outcomes: a systematic review and meta-analysis. Am J Obstet Gynecol. 2011;205(3):219.e1-7.

10 Kwiatkowski MA, Roos A, Stein DJ, Thomas KG, Donald K. Effects of prenatal methamphetamine exposure: a review of cognitive and neuroimaging studies. Metab Brain Dis. 2014;29(2):245-54
11 Smith LM, Diaz S, LaGasse LL, Wouldes T, Derauf C, Newman E, et al. Developmental and behavioral consequences of prenatal methamphetamine exposure: a review of the infant development, environment, and lifestyle (IDEAL) study. Neurotoxicol Teratol. 2015 Sep-Oct;51:35-44.

12 Gabrhelík R, Skurtveit S, Nechanská B, Handal M, Mahic M, Mravčík V. Prenatal methamphetamine exposure and adverse neonatal outcomes: a nationwide cohort study. Eur Addict Res. 2021:27:97-106.

13 Šlamberová R, Vrajová M, Schutová B, Mertlová M, Macúchová E, Nohejlová K, et al. Prenatal methamphetamine exposure induces long-lasting alterations in memory and development of NMDA receptors in the hippocampus. Physiol Res. 2014;63(Suppl 4):S54758.

14 Dong N, Zhu J, Han W, Wang S, Yan Z, Ma $\mathrm{D}$, et al. Maternal methamphetamine exposure causes cognitive impairment and alteration of neurodevelopment-related genes in adult offspring mice. Neuropharmacology. 2018; $140: 25-34$.

15 Dodd V. Gestational age assessment. Neonatal Netw. 1996 Feb;15(1):27-36.

16 Chen R, Tedroff K, Villamor E, Lu D, Cnattingius S. Risk of intellectual disability in children born appropriate-for-gestationalage at term or post-term: impact of birth weight for gestational age and gestational age. Eur J Epidemiol. 2020 Mar;35(3):27382.

17 Domellöf E, Johansson A-M, Farooqi A, Domellöf M, Rönnqvist L. Risk for behavioral problems independent of cognitive functioning in children born at low gestational ages. Front Pediatr. 2020 Jun 26;8:311.

18 Abar B, LaGasse LL, Derauf C, Newman E, Shah R, Smith LM, et al. Examining the relationships between prenatal methamphetamine exposure, early adversity, and child neurobehavioral disinhibition. Psychol Addict Behav. 2013;27(3):662-73.
19 Kiblawi ZN, Smith LM, LaGasse LL, Derauf C, Newman E, Shah R, et al. The effect of prenatal methamphetamine exposure on attention as assessed by continuous performance tests: results from the infant development, environment, and lifestyle study. J Dev Behay Pediatr. 2013;34(1):31-7.

20 LaGasse LL, Derauf C, Smith LM, Newman E, Shah R, Neal C, et al. Prenatal methamphetamine exposure and childhood behavior problems at 3 and 5 years of age. Pediatrics. 2012;129(4):681-8.

21 Diaz SD, Smith LM, LaGasse LL, Derauf C, Newman E, Shah R, et al. Effects of prenatal methamphetamine exposure on behavioral and cognitive findings at 7.5 years of age. J Pediatr. 2014;164(6):1333-8.

22 Smith L, Yonekura ML, Wallace T, Berman N, Kuo J, Berkowitz C. Effects of prenatal methamphetamine exposure on fetal growth and drug withdrawal symptoms in infants born at term. J Dev Behav Pediatr. 2003, 24(1):17-23

23 Derauf C, Lagasse LL, Smith LM, Newman E, Shah R, Neal CR, et al. Prenatal methamphetamine exposure and inhibitory control among young school-age children. J Pediatr. 2012;161(3):452-9.

24 Eze N, Smith LM, LaGasse LL, Derauf C, Newman E, Arria A, et al. School-aged outcomes following prenatal methamphetamine exposure: 7.5-year follow-up from the infant development, environment, and lifestyle study. J Pediatr. 2016;170:34-8.e1.

25 Wouldes TA, Lagasse LL, Huestis MA, Dellagrotta S, Dansereau LM, Lester BM. Prenatal methamphetamine exposure and neurodevelopmental outcomes in children from 1 to 3 years. Neurotoxicol Teratol. 2014 MarApr;42:77-84.

26 Shah R, Diaz SD, Arria A, LaGasse LL, Derauf C, Newman E, et al. Prenatal methamphetamine exposure and short-term maternal and infant medical outcomes. Am J Perinatol. 2012;29(5):391-400. 
27 Bigelow CA, Naqvi M, Namath AG, Ali M, Fox NS. Cervical length, cervical dilation, and gestational age at cerclage placement and the risk of preterm birth in women undergoing ultrasound or exam indicated shirodkar cerclage. J Matern Fetal Neonatal Med. 2020; 33(15):2527-32.

28 Crump C, Sundquist J, Sundquist K. Preterm birth and risk of type 1 and type 2 diabetes: a national cohortstudy. Diabetologia. 2020; 63(3):508-18.

29 Mugnier A, Mila H, Guiraud F, Brévaux J, Lecarpentier M, Martinez C, et al. Birth weight as a risk factor for neonatal mortality: breed-specific approach to identify at-risk puppies. Prev Vet Med. 2019;171:104746.

30 Vilanova CS, Hirakata VN, de Souza Buriol VC, Nunes M, Goldani MZ, da Silva CH. The relationship between the different low birth weight strata of newborns with infant mortality and the influence of the main health determinants in the extreme south of brazil. Popul Health Metr. 2019;17(1):15.

31 Jackson DC, Lin JJ, Chambers KL, KesslerJones A, Jones JE, Hsu DA, et al. Birth weight and cognition in children with epilepsy. Epilepsia. 2014;55(6):901-8.

32 Momany AM, Kamradt JM, Nikolas MA. A meta-analysis of the association between birth weight and attention deficit hyperactivity disorder. J Abnorm Child Psychol. 2018; 46(7):1409-26.

33 Raslau D, Herrick LM, Locke GR, Schleck CD, Zinsmeister AR, Almazar A, et al. Irritable bowel syndrome and the perinatal period: lower birth weight increases the risk. Neurogastroenterol Motil. 2016;28(10):1518-24.

34 Lai C, Hu Y, He D, Liang L, Xiong F, Liu G, et al. U-shaped relationship between birth weight and childhood blood pressure in China. BMC Pediatr. 2019;19(1):264.

35 Little BB, Snell LM, Gilstrap LC. III methamphetamine abuse during pregnancy: outcome and fetal effects. Obstet Gynecol. 1988;72: 541-4.

36 Chomchai C, Na Manorom N, Watanarungsan $\mathrm{P}$, Yossuck P, Chomchai S. Methamphetamine abuse during pregnancy and its health impact on neonates born at Siriraj Hospital, Bangkok, Thailand. Southeast Asian J Trop Med Public Health. 2004;35(1): 228-31.

37 Phupong V, Darojn D. Amphetamine abuse in pregnancy: the impact on obstetric outcome. Arch Gynecol Obstet. 2007;276(2): $167-70$.

38 Harris SR. Measuring head circumference: update on infant microcephaly. Can Fam Physician. 2015;61(8):680-4.

39 Garza C. Fetal, neonatal, infant, and child international growth standards: an unprecedented opportunity for an integrated approach to assess growth and development. Adv Nutr. 2015;6(4):383-90.
40 Aagaard K, Matthiesen NB, Bach CC, Larsen RT, Henriksen TB. Head circumference at birth and intellectual disability: a nationwide cohort study. Pediatr Res. 2020;87(3):595601.

41 Dixon SD, Bejar R. Echoencephalographic findings in neonates associated with maternal cocaine and methamphetamine use: incidence and clinical correlates. J Pediatr. 1989; 115(5 Pt 1):770-8.

42 Winslow BT, Voorhees KI, Pehl KA. Methamphetamine abuse. Am Fam Physician. 2007;76(8):1169-74

43 LaGasse LL, Wouldes T, Newman E, Smith LM, Shah RZ, Derauf C, et al. Prenatal methamphetamine exposure and neonatal neurobehavioral outcome in the USA and New Zealand. Neurotoxicol Teratol. 2011 Jan-Feb; 33(1):166-75

44 Kato T, Yorifuji T, Inoue S, Doi H, Kawachi I. Association of birth length and risk of hospitalisation among full-term babies in Japan. Paediatr Perinat Epidemiol. 2013;27(4):36170.

45 Baran J, Weres A, Czenczek-Lewandowska E, Leszczak J, Kalandyk-Osinko K, Mazur A. Relationship between children's birth weight and birth length and a risk of overweight and obesity in 4-15-year-old children. Medicina. 2019;55(8):487.

46 Apgar V. A proposal for a new method of evaluation of the newborn infant. Originally published in July 1953 , volume 32 , pages 250 259. Anesth Analg. 2015;120(5):1056-9.

47 American Academy of Pediatrics Committee on Fetus and Newborn, American College of Obstetricians and Gynecologists Committee on Obstetric Practice. The apgar score. Pediatrics 2015;136(4):819-22.

48 Good MM, Solt I, Acuna JG, Rotmensch S, Kim MJ. Methamphetamine use during pregnancy: maternal and neonatal implications. Obstet Gynecol. 2010;116(2 Pt 1):330-4.

49 Kalaitzopoulos DR, Chatzistergiou K, Amylidi AL, Kokkinidis DG, Goulis DG. Effect of methamphetamine hydrochloride on pregnancy outcome: a systematic review and meta-analysis. J Addict Med. 2018 May/Jun; 12(3):220-6.

50 Billing L, Eriksson M, Larsson G, Zetterström R. Amphetamine addiction and pregnancy. III. One year follow-up of the children. Psychosocial and pediatric aspects. Acta Paediatr Scand. 1980;69(5):675-80.

51 Smith LM, Lagasse LL, Derauf C, Grant P, Shah R, Arria A, et al. Prenatal methamphetamine use and neonatal neurobehavioral outcome. Neurotoxicol Teratol. 2008 Jan-Feb; 30(1):20-8

52 Oei J, Abdel-Latif ME, Clark R, Craig F, Lui K. Short-term outcomes of mothers and infants exposed to antenatal amphetamines. Arch Dis Child Fetal Neonatal Ed. 2010;95(1): F36-41.
53 Smith LM, Paz MS, LaGasse LL, Derauf C, Newman E, Shah R, et al. Maternal depression and prenatal exposure to methamphetamine: neurodevelopmental findings from the infant development, environment, and lifestyle (ideal) study. Depress Anxiety. 2012;29(6):51522.

54 Twomey J, LaGasse L, Derauf C, Newman E, Shah R, Smith L, et al. Prenatal methamphetamine exposure, home environment, and primary caregiver risk factors predict child behavioral problems at 5 years. Am J Orthopsychiatry. 2013;83(1):64-72.

55 Cloak CC, Ernst T, Fujii L, Hedemark B, Chang L. Lower diffusion in white matter of children with prenatal methamphetamine exposure. Neurology. 2009;72(24):2068-75.

56 Warton FL, Meintjes EM, Warton CMR, Molteno CD, Lindinger NM, Carter RC, et al. Prenatal methamphetamine exposure is associated with reduced subcortical volumes in neonates. Neurotoxicol Teratol. 2018 JanFeb;65:51-9.

57 Chang L, Oishi K, Skranes J, Buchthal S, Cunningham E, Yamakawa R, et al. Sex-specific alterations of white matter developmental trajectories in infants with prenatal exposure to methamphetamine and tobacco. JAMA Psychiatry. 2016;73(12):1217-27.

58 Derauf C, Lester BM, Neyzi N, Kekatpure M, Gracia L, Davis J, et al. Subcortical and cortical structural central nervous system changes and attention processing deficits in preschool-aged children with prenatal methamphetamine and tobacco exposure. Dev Neurosci. 2012;34(4):327-41.

59 Sowell ER, Leow AD, Bookheimer SY, Smith LM, O'Connor MJ, Kan E, et al. Differentiating prenatal exposure to methamphetamine and alcohol versus alcohol and not methamphetamine using tensor-based brain morphometry and discriminant analysis. J Neurosci. 2010 Mar 17;30(11):3876-85.

60 Roos A, Jones G, Howells FM, Stein DJ, Donald KA. Structural brain changes in prenatal methamphetamine-exposed children. Metab Brain Dis. 2014;29(2):341-9.

61 Roos A, Kwiatkowski MA, Fouche JP, Narr KL, Thomas KG, Stein DJ, et al. White matter integrity and cognitive performance in children with prenatal methamphetamine exposure. Behav Brain Res. 2015;279:62-7.

62 Roos A, Fouche JP, du Toit S, du Plessis S, Stein DJ, Donald KA. Structural brain network development in children following prenatal methamphetamine exposure. J Comp Neurol. 2020;528(11):1856-63.

63 Warton FL, Taylor PA, Warton CMR, Molteno CD, Wintermark $\mathrm{P}$, Lindinger NM, et al. Prenatal methamphetamine exposure is associated with corticostriatal white matter changes in neonates. Metab Brain Dis. 2018; 33(2):507-22. 
64 Warton FL, Taylor PA, Warton CMR, Molteno CD, Wintermark P, Zöllei L, et al. Reduced fractional anisotropy in projection, association, and commissural fiber networks in neonates with prenatal methamphetamine exposure. Dev Neurobiol. 2020;80(11-12): 381-98.

65 Roussotte FF, Rudie JD, Smith L, O'Connor MJ, Bookheimer SY, Narr KL, et al. Frontostriatal connectivity in children during working memory and the effects of prenatal methamphetamine, alcohol, and polydrug exposure. Dev Neurosci. 2012;34(1):43-57.

66 Billing L, Eriksson M, Steneroth G, Zetterström R. Predictive indicators for adjustment in 4-year-old children whose mothers used amphetamine during pregnancy. Child Abuse Negl. 1988;12(4):503-7.

67 Chang L, Smith LM, LoPresti C, Yonekura ML, Kuo J, Walot I, et al. Smaller subcortical volumes and cognitive deficits in children with prenatal methamphetamine exposure. Psychiatry Res. 2004;132(2):95-106.
68 Colby JB, Smith L, O'Connor MJ, Bookheimer SY, Van Horn JD, Sowell ER. White matter microstructural alterations in children with prenatal methamphetamine/ polydrug exposure. Psychiatry Res. 2012; 204(2-3):140-8.

69 Billing L, Eriksson M, Jonsson B, Steneroth G, Zetterström R. The influence of environmental factors on behavioural problems in 8-year-old children exposed to amphetamine during fetal life. Child Abuse Negl. 1994; 18(1):3-9.

70 Eriksson M, Zetterström R. Amphetamine addiction during pregnancy: 10-year followup. Acta Paediatr Suppl. 1994;404:27-31.

71 Cernerud L, Eriksson M, Jonsson B, Steneroth G, Zetterström R. Amphetamine addiction during pregnancy: 14-year follow-up of growth and school performance. Acta Paediatr. 1996;85(2):204-8.

72 Smith LM, LaGasse LL, Derauf C, Newman E, Shah R, Haning W, et al. Motor and cognitive outcomes through three years of age in children exposed to prenatal methamphetamine. Neurotoxicol Teratol. 2011 Jan-Feb;33(1): $176-84$.
73 Huntley M. The griffiths mental development scales from birth to 2 years. Oxford: The Test Agency Limited; 1996.

74 O'Connor A, Seeber C, Harris E, Hamilton D, Sachmann M, Fisher C. Developmental outcomes following prenatal exposure to methamphetamine: a Western Australian perspective. J Paediatr Child Health. 2020;56(3):3728.

75 van Dyk J, Ramanjam V, Church P, Koren G, Donald K. Maternal methamphetamine use in pregnancy and long-term neurodevelopmental and behavioral deficits in children. Popul Ther Clin Pharmacol. 2014;21(2): e185-96.

76 Oni-Orisan OO, Dansereau LM, Marsit CJ, Smith LM, Neal CR, Della Grotta SA, et al. DNA methylation in children with prenatal methamphetamine exposure and environmental adversity. Pediatr Res. 2021;89(5): $1152-6$ 